\title{
Lazarenkia (Pottiaceae, Bryopsida) - a new genus of mosses and Lazarenkia kozlovii - a new combination at species rank
}

\author{
MYKHAILO FEDOSIJOVYCH BOIKO
}

БОЙКО М.Ф., 2011: Lazarenkia (Pottiaceae, Bryopsida) - новий рід мохів та нова видова комбінація - Lazarenkia kozlovii. Чорноморськ. бот. ж., Т.7, № 4: 400-402.

В статті подаються матеріали щодо опису нового роду мохоподібних - Lazarenkia Boiko (Pottiaceae, Bryopsida), який включає один вид - Lazarenkia kozlovii. Назва Lazarenkia дана на честь видатного українського бріолога А.С.Лазаренка.

Ключові слова: Bryopsida, новий pid, Lazarenkia, Lazarenkia kozlovii

BOIKO M.F., 2011: Lazarenkia (Pottiaceae, Bryopsida) - a new genus of mosses and Lazarenkia kozlovii - a new combination at species rank. Chornomorsk. bot. z., Vol. 7 , № 4: 400-402.

A new genus of bryophytes Lazarenkia Boiko (Pottiaceae, Bryopsida) is described with giving the name in honour of famous Ukrainian bryologist A.S.Lazarenko. The genus Lazarenkia includes one species - Lazarenkia kozlovii.

Key words: Bryopsida, new genus, Lazarenkia, Lazarenkia kozlovii

БОЙКО М.Ф., 2011: Lazarenkia (Pottiaceae, Bryopsida) - новый род мхов и новая видовая комбинация - Lazarenkia kozlovii. Черноморск. бот. ж., Т.7 № 4: 400-402.

В статье приводятся материалы к описанию нового рода Lazarenkia Boiko (Pottiaceae, Bryopsida), который включает один вид - Lazarenkia kozlovii. Название рода Lazarenkia дано в честь выдающегося украинского бриолога А.С.Лазаренко.

Ключевые слова: Bryopsida, новый род, Lazarenkia, Lazarenkia kozlovii

The world known bryologist Andriy Lazarenko described Pterygoneurum kozlovii Lazar. in 1936 with further valid publication in 1946 [ЛАЗАРЕНКО, 1946] (Pterygoneurum kozlovii Lazar., 1946, Ботан. журн. АН Укр. PCР, III, 3-4: 61-63). The species epithet was given by him in honour of A.Kozlov, who was the first to find this plant in Zaporizhzhya region of Ukraine.

Many authors [ЛАЗАРЕНКО 1936, 1946, 1955; БАЧУРИНА, 1960; АБРАМОВА, БЛАГОДАТСКИХ, ЧЕРЕПАНОВА, 1973; ZANDER, 1993, 2003; ИГНАТОВ, ИГНАТОВА, 2003; PISARENKO, 2006; ZHAO D.-P., BAI, ZHAO N., 2007, et al] point out that P. kozlovii differs considerably from all other species of genus Pterygoneurum. This distinction made Lazarenko assumed the hybrid origin of $P$. kozlovii from species belonged to Pterygoneurum and Phascum. Later this hypothesis was rejected in favor of non-hybrid intermediate position $P$. kozlovii between Pterygoneurum and Phascum. H.F.Bachurina [1960] considered this species to be a result of later evolution of a species in specific conditions of carbonate salinity.

Thus, specificity of features, their dissimilarity with the genus' features gives us the reason to bring this species out of the Pterygoneurum genus and submit it as a new separate genus Lazarenkia (named after Andriy S. Lazarenko) with one widespread (Europe, Asia, North America) species - Lazarenkia kozlovii.

(C) М.Ф. Бойко

Чорноморськ. бот. ж., Т. 7, № 4: 400-402. 
The genus Lazarenkia differs from genus Pterygoneurum with cleistocarpous capsule and leaf veins provided with small elongated green assimilation scales of 2-4 (6) cell rows; plants of genus Phascum has no any assimilation scales on their leaves. Evolutionary, the genus Lazarenkia takes intermediate place between Pterygoneurum and Phascum (see Table).

Lazarenkia Boiko gen. nov.

Descriptio. - Planta laete virida vel luteovirens. Capsula cleistocarpa, globosa vel ovoidea, inter folia perichaetialia abscondita. Folia cum lamellae assimilatoriae e 1-3 (4) seriebus cellularum formatae. Pili hyalini breves. Sporae magnae, $34-47 \mathrm{mkm}$ in diam., luteae, aliquatenus dense papillosae, cum ornamemtatio specifica.

Holotypus. Ucrainia, regio Zaporizhzhya, prope urbem Kamyanka-Dniprovska, in salsis sabulosis. A. Kozlov legit, A.S. Lazarenko determinavit. In KW conservatur.

Description. Plant light green, rarely yellowish. Cleistocarpous capsule globose to ovoid, fully embedded into perichaetial leaves. Assimilation scales on the leaf of 2-4 (6) cells. Hyaline hairs are relatively short. Spores large $(34-47 \mathrm{mcm})$, yellow, relatively dense papillate and specifically ornamented.

Comparative characteristics of genera Pterygoneurum, Lazarenkia, Phascum

Table 1

\begin{tabular}{|l|l|l|}
\hline \multicolumn{1}{|c|}{ Pterygoneurum } & \multicolumn{1}{|c|}{ Lazarenkia } & \multicolumn{1}{c|}{ Phascum } \\
\hline Capsule stegocarpous & Capsule cleistocarpous & Capsule cleistocarpous \\
\hline $\begin{array}{l}\text { Ventral leaf side rib with well } \\
\text { developed green scales of 2-6 } \\
\text { cell rows }\end{array}$ & $\begin{array}{l}\text { Ventral leaf side rib with } \\
\text { poorly developed green } \\
\text { scales of 1-3 (4) cell rows }\end{array}$ & $\begin{array}{l}\text { Ventral leaf side rib without } \\
\text { green scales }\end{array}$ \\
\hline Capsule pedicellate & $\begin{array}{l}\text { Capsule sessile, fully } \\
\text { embedded into perichaetial } \\
\text { leaves }\end{array}$ & $\begin{array}{l}\text { Capsule embedded into } \\
\text { perichaetial leaves or } \\
\text { protrudes laterally }\end{array}$ \\
\hline Spores 14-35 mkm & Spores 34-47 mkm & $\begin{array}{l}\text { Spores 18-32 mkm } \\
\text { Plants yellow-green to dark } \\
\text { green or russet }\end{array}$ \\
\hline $\begin{array}{l}\text { Plants dark-green to blackish, } \\
\text { often grayish of hyaline hairs }\end{array}$ & Plants light-green & \multicolumn{2}{|c|}{ or } \\
\hline
\end{tabular}

\section{Combination at the species rank:}

Lazarenkia kozlovii (Lasar.) Boiko comb. nov. - Basionim: Pterygoneurum kozlovii Lazar., 1946, Ботан. журн. АН Укр. РСР, III, 3-4: 61-63.

The new genus includes one species Lazarenkia kozlovii (Lasar.) Boiko. with characters described above.

\section{References}

АБРАМОВА Л.А., БЛАГОДАТСКИХ Л.С., ЧЕРЕПАНОВА Л.А. Обзор рода Pterygoneurum Jur (Musci) в СССР // Новости сист. низш. раст. - 1973. - Т.10. - С. 305-316.

БАчУРИНА Г.Ф. До флори мохів південно-західної частини Одеської області // Укр. ботан. журн. - 1960. Т. 17, № 2. - C.83-88.

БАчУРИНА Г.Ф., МЕльничУк В.М. Флора мохів Української РСР. Вип. 2. - Київ: Наук. думка, 1988. - 180 c.

Бойко М.Ф. Мохоподібні степової зони України. - Херсон: Айлант, 2009. - 264 с.

ИгнАтов М. С., ИгнатовА Е. А. Флора мхов средней части европейской России. Т.1: Spagnaceae Hedwigiaceae. (Arctoa, т.1, прилож.1). - Москва: КМК., 2003. - С.1-608 с.

ЛАЗАРЕНКО А.С. ВизНачник листяних мохів УРСР. - Київ, 1936. - 105 с.

ЛАЗАРЕНКО А.С. Бріологічні нотатки //Ботан. журн АН УРСР. - 1946. - Т.ІІІ, № 3-4. - С. 61-63.

ЛАЗАРЕНКО А.С. Определитель лиственных мхов Украины.-Киев: Изд-во АН УССР, 1955. - 466 с.

МЕльничук В. М. Определитель лиственных мхов средней полосы и юга Европейской частти СССР. Киев: Наук. думка, 1970. - 442 с.

САВИЧ-ЛЮБИЦКАЯ Л.И., СМИРНОВА 3.Н. Определитель листостебельных мхов СССР. Верхоплодные мхи. - Л.:Наука, 1970. - 824 с. 
FREY W., FrAhM J.-P, Fischer E., LobIN W. Die Moos- und Farnpflanzen Europas // Kleine Kryptogamenflora. - Band IV. - Stuttgart ·Jena ·New York: G. F. Verlag, 1995. - $426 \mathrm{~s}$.

PISARENKo O.YU. Of the variation and ecology of Pterygoneurum subsessile and P. kozlovii (Pottiaceae, Bryophyta) // Arctoa. - 2006. - Vol. 15. - P. 169-182.

ZANDER R.H. Genera of the Pottiaceae: Mosses of Harsh Enviroments // Bull. Buffalo Soc. Nat. Sci. - 1993. Vol. 32. - P. 1-378.

ZANDER R.H. Pterygoneurum. - Bryophyte Flora of North America, Provisional Publication. Buffalo Museum of Science. - 2003. www. buffalomuseumosscience.org/ BFNA/ bfnamenu. htm

Zhao D.-P., Bai X-L., Zhao N. Genus Pterygoneurum (Pottiaceae, Musci) in China // Ann. Bot. Fennici. 2007. - Vol. 45. - P. 121-128.

Рекомендує до друку

Отримано 11.12. 2011 p.

А.В. Сна

\section{Aдреса автора:}

М.Ф. Бойко

Херсонський державний університет

вул. 40 років Жовтня, 27, Херсон, 73000

Україна

e-mail:bomifed@ksu.ks.ua

\author{
Autor's address: \\ M.F. Boiko \\ The Kherson State University \\ 27, 40 Rokiv Zhovtnya str., Kherson, 73000 \\ Ukraine \\ e-mail: bomifed@ksu.ks.ua
}

